\title{
ЗоОЛОГИя
}

УДК 574.34:599.323.43

doi: $10.17223 / 19988591 / 32 / 3$

\section{Н.Л. Добринский}

Институт экологии растений и животных УрО РАН, г. Екатеринбург, Россия

\section{Трофический фактор и локальная хорологическая структура населения грызунов на примере лесных полевок}

\begin{abstract}
На основании длительных экспериментов в природе с использованием дополнительной подкормки определены основные закономерности $u$ количественные параметры формирования "стаций переживания» грызунов на модели рыжей лесной полевки (Clethrionomys glareolus Schreber, 1780). Установлена ведущая роль трофического фактора в прочессах функиионирования населения лесных полевок на локальном уровне в снежный период. Показано, что при достижении порогового уровня кормообеспеченности происходит облигатное образование устойчивых элементарных хорологических ячеек (хорусов) видового населения на основе генетической преемственности нескольких последовательных поколений грызунов. Одновременное применение как регрессионного, так и стохастического математических методов впервые позволило обнаружить явление возвратной ротации населения полевок $c$ образованием центральных и периферических переходных зон, что обеспечивает виду в снежный период наиболее эффективное использование трофических ресурсов среды с сохранением максимально возможной численности. При этом автономные поселения грызунов размером от одного до нескольких гектаров функиионируют как локальные градиентные континуумы видового населения.

Ключевые слова: трофический фактор; грызуны; население; динамика численности; эксперименты; подкормка.
\end{abstract}

\section{Введение}

Проблемы популяционной организации и динамики видового населения наземных позвоночных животных длительное время находятся в центре внимания широкого круга исследователей и до настоящего времени остаются дискуссионными [1-15]. Особую актуальность вопросы популяционной экологии грызунов, в частности лесных полевок как традиционных и наиболее удобных модельных объектов, приобретают в результате оформления метапопуляционной экологии [16-17]. В связи с этим нами предпринята попытка на основе широкого научного синтеза с использованием оригинальных результатов длительных стационарных исследований разработать объе- 
динительную концепцию элементарной хорологической структуры видового населения животных [18]. Центральным понятием концепции для локального масштаба от одного до нескольких гектаров является элементарная хорологическая ячейка видового населения, или хорус. Соответствующие этому понятию реально существующие территориально-пространственные ячейки населения определенного вида наделены функциональным единством и способностью к автономному существованию, по крайней мере, в продолжение нескольких последовательных поколений. Кроме того, элементарные (только в смысле дальнейшей неделимости без потери основополагающих свойств) хорологические единицы видового населения характеризуются целым набором специфических свойств. Учитывая весь комплекс их параметров, они не могут быть тождественны ни одному из таких общеизвестных понятий, как «биотип», «экоэлемент», «темпоральная популяция», «менделевская популяция», «дем», «парцелла», «мерус», «микропопуляция» и «элементарная популяция». В этой связи необходимо подчеркнуть, что все вышеперечисленные понятия относятся к принципиально иным формам организации видового населения, главной особенностью которых является неспособность к самостоятельному автономному существованию в ряду последовательно сменяющих друг друга поколений.

Поскольку одним из ведущих экологических факторов является трофический [19-26], особое значение приобретает количественная оценка его роли в функционировании так называемых «стаций переживания» неблагоприятных условий в зимний период [27]. Лабильная сеть, состоящая из определенного набора таких стаций, может, по всей вероятности, иметь решающее значение в формировании локальной хорологической структуры видового населения грызунов на конкретной местности. С целью точной количественной оценки динамичных процессов формирования и функционирования базовых элементарных хорологических ячеек населения грызунов нами в рамках непрерывных (с 1983 по 2014 г.) исследований проведены длительные круглогодичные эксперименты в природе с использованием строго дозированных дополнительных кормовых ресурсов.

\section{Материалы и методики исследования}

Работа основана на результатах длительных экспериментальных исследований динамики населения грызунов на Среднем Урале в условиях типичных южнотаежных биогеоценозов коренного типа. Первичный полевой материал включает детальные данные по мечению и повторным отловам грызунов на стационарных неогороженных площадках размером от 0,5 до 1 га.

Для получения наиболее полных и точных результатов при интенсивной работе с населением грызунов на относительно небольших территориях применяли метод пожизненного мечения [28]. Использовали деревянные ящичные ловушки с качающимся трапом, которые в течение всего периода 
исследований находились в углах квадратной сетки со стороной 8 м. Отловы проводили сериями по 4-5 сут с двумя проверками - утром и вечером. Ежегодно проводили от 2 до 5 серий отловов с февраля по декабрь. В промежутках между сериями приманку не применяли, задние крышки всех живоловок оставляли открытыми, а все ловушки накрывали специально изготовленными крышками для защиты от атмосферных осадков. На контролируемых территориях в условиях типичных для южной тайги биотопов всегда доминировала рыжая полевка (Clethrionomys glareolus Schreber, 1780). Поэтому локальные поселения этого вида использованы в качестве модельных объектов. За весь период полевых экспериментов отловлено и помечено более 500 рыжих полевок и зарегистрировано более 1500 заходов животных в ловушки. У всех отловленных животных определяли массу тела, пол, возраст по данным мечения и репродуктивный статус.

Полевые эксперименты с применением подкормки проводили круглогодично и непрерывно в течение трех последовательных лет. Подкормку (овес) помещали в 100 кормушек оригинальной конструкции, которые расставляли по территории опытной площадки мечения размером 1 га. Контролем служила такая же по размеру отдельная площадка мечения, расположенная на расстоянии 0,7 км в сходном биотопе. За весь период исследований израсходовано 300 кг подкормки. Необходимо отметить, что оригинальная конструкция кормушек обеспечивала как надежную защиту подкормки от атмосферных осадков, так и доступ к ней только мышевидным грызунам. По мере потребления подкормки проводили ее регулярное добавление таким образом, чтобы зерна овса всегда находились в кормушках.

Поскольку отловы животных проводили во все сезоны года, на каждой площадке в точках отлова устанавливали вертикальные цилиндры из водостойкого картона диаметром 80 см и высотой 120 см. Сверху их закрывали металлическими крышками. В зимний период для защиты от снега ловушки устанавливали внутрь цилиндров на поверхность почвы.

Для статистического анализа учетных данных одновременно применяли как регрессионный метод Лесли [29] в модификации Хейне [30], так и стохастический метод Джолли-Зебера [31-32] и стандартные статистические критерии. Статистическая обработка полученных данных выполнена в программе Statsoft STATISTICA for Windows 6.0. Кроме того, использовали и наиболее полные первичные учетные данные тотальных отловов, которые соответствуют общей (генеральной) или ротационной численности полевок на контролируемой территории в определенные промежутки времени. На наш взгляд, это оправдано, потому что при правильном проведении отловов с соблюдением необходимых требований методики за 4-5 сут в ловушки попадают практически все оседлые и регулярно посещающие площадки грызуны. Поэтому анализ результатов охватывает всю реально существующую совокупность особей, населяющих в данный период учетную площадь. 


\section{Результаты исследования и обсуждение}

Первые серии отловов проведены летом на опытной и контрольной площадках мечения до начала использования подкормки в период предельно высокой численности рыжей полевки (124 экз./га). В этот период общая (генеральная) численность грызунов находилась на одном уровне на обеих площадках и не отличалась от численности, рассчитанной по методу Лесли (таблица). Во время внесения первой порции подкормки осенью первого года статистически значимых различий между двумя упомянутыми показателями также не зафиксировано. Эта закономерность в целом сохранялась во все годы и сезоны проведения исследований, что подтверждает возможность использования общей или генеральной (ротационной) численности наравне с численностью, рассчитанной по методу Лесли при соблюдении необходимых условий вылова. Данная закономерность свидетельствует в пользу того, что за первые 4-5 сут непрерывных отловов в живоловушки с приманкой заходит подавляющее большинство оседлых и регулярно посещающих площадки животных. Однако следует отметить закономерное увеличение статистической ошибки при расчетах численности полевок регрессионным методом в сложные для их существования осенние и весенние периоды межсезонья, когда значительно увеличивается территориальная активность грызунов. Причиной этого явления служит изменение монотонности убывания суточных уловов и, как следствие, нарушение стандартного соотношения накопленного улова и отдельных суточных уловов.

Последовательный анализ данных по сезонной и годовой динамике численности рыжей полевки, определенной по методике Лесли, в сравнении с рассчитанной по методу Джолли-Зебера, позволил выделить следующие закономерности. После внесения первой порции подкормки численность лесных полевок осенью первого года экспериментов, определенная вероятностным методом, по результатам 2-й серии отловов в 3 раза превысила полученные регрессионным методом показатели в опыте (t-критерий $=2,75$; $\mathrm{p}<0,01)$ (см. таблицу).

Следует отметить, что снижение обилия грызунов в контроле продолжилось и в декабре (3-я серия отловов), а в дальнейшем показатели численности снизились здесь до минимальных значений. Глубокая депрессия численности полевок вплоть до нулевых отметок продолжалась на контрольной площадке без перерыва до окончания экспериментов. Напротив, в опыте регрессионная численность животных даже увеличилась в период 3-й серии отловов, но на фоне возросшей статистической ошибки этот рост оказался статистически не подтвержденным. Тем не менее показатели общей или генеральной (ротационной) численности однозначно свидетельствуют, по крайней мере, об их сохранении на уровне предыдущей 2-й серии отловов. На этом фоне особого внимания заслуживает рост показателей согласно вероятностной модели определения численности полевок во время 3-й серии 
отловов. При этом численность грызунов, рассчитанная по методу ДжоллиЗебера в опыте, статистически значимо превысила таковую по методу Лесли ( $\mathrm{t}$-критерий $=2,19 ; \mathrm{p}<0,05)$.

Следует отметить, что данная закономерность обычно не фиксируется в осенне-зимний период, так как на большей части территории в это время после прекращения размножения происходит массовая гибель лесных полевок и, соответственно, резкое снижение уровня численности животных. Учитывая отмеченную закономерность, осенне-зимний период существования грызунов можно определить как стадию своеобразной локализации (агрегации) видового населения в так называемых «стациях переживания» неблагоприятных условий.

Численность рыжих полевок (экз. на 0,5 га)* на опытной и контрольной площадках мечения по результатам тотального индивидуального мечения и повторных отловов животных [Number of bank voles (animals per 0.5 hectare)* on experimental and control plots according to the results of total individual marking and repeated catching of animals]

\begin{tabular}{|c|c|c|c|c|c|}
\hline \multirow{3}{*}{$\begin{array}{c}\text { Годы и сезоны } \\
\text { отдельных серий } \\
\text { отловов } \\
\text { [Years and seasons } \\
\text { of separate series } \\
\text { of captures] }\end{array}$} & \multicolumn{2}{|c|}{$\begin{array}{l}\text { Общая числен- } \\
\text { ность, экз. } \\
\text { [General number] }\end{array}$} & \multicolumn{2}{|c|}{$\begin{array}{c}\text { Численность по } \\
\text { методу Лесли, экз. } \\
\text { [Number of animals } \\
\text { according to Leslie method] }\end{array}$} & \multirow{2}{*}{$\begin{array}{c}\text { Численность по } \\
\text { методу Джолл- } \\
\text { Зебера, экз. ** } \\
\text { [Number of animals } \\
\text { according to Jolly- } \\
\text { Seber method] } \\
\text { Oпыт } \\
\text { [Experiment] }\end{array}$} \\
\hline & $\begin{array}{c}\text { Контроль } \\
\text { [Control] }\end{array}$ & $\begin{array}{c}\text { Опыт } \\
\text { [Experi- } \\
\text { ment] }\end{array}$ & $\begin{array}{c}\text { Контроль } \\
\text { [Control] }\end{array}$ & $\begin{array}{c}\text { Опыт } \\
\text { [Experiment] }\end{array}$ & \\
\hline & $N$ & $N$ & $\begin{array}{l}- \\
X\end{array}$ & $\begin{array}{l}- \\
X\end{array}$ & $\begin{array}{l}- \\
X\end{array}$ \\
\hline $\begin{array}{l}\text { Первый год, август, } \\
1 \text {-я серия } \\
\text { [First year August } \\
1 \text { series] } \\
\end{array}$ & 61 & 62 & $59,1 \pm 8,0$ & $60,77 \pm 12,65$ & - \\
\hline $\begin{array}{l}\text { Первый год, октябрь, } \\
2 \text {-я cерия *** } \\
\text { [First year October } \\
2 \text { series] } \\
\end{array}$ & 10 & 25 & $11,0 \pm 9,2$ & $27,08 \pm 0,19$ & $80,56 \pm 19,42$ \\
\hline $\begin{array}{l}\text { Первый год, декабрь, } \\
3 \text {-я серия } \\
\text { [First year December } \\
3 \text { series] } \\
\end{array}$ & 6 & 23 & $6,1 \pm 3,0$ & $36,56 \pm 13,07$ & $113,36 \pm 32,52$ \\
\hline $\begin{array}{l}\text { Второй год, февраль, } \\
\text { 4-я серия } \\
\text { [Second year February } \\
4 \text { series] } \\
\end{array}$ & 1 & 61 & - & $92,16 \pm 20,68$ & $78,01 \pm 9,27$ \\
\hline $\begin{array}{l}\text { Второй год, апрель, } \\
\text { 5-я серия } \\
\text { [Second year April } \\
5 \text { series] } \\
\end{array}$ & - & 42 & - & $45,47 \pm 2,24$ & $69,3 \pm 13,93$ \\
\hline
\end{tabular}


О к о н ч н и е т а б л ц ы [Table end]

\begin{tabular}{|c|c|c|c|c|c|}
\hline \multirow{3}{*}{$\begin{array}{c}\text { Годы и сезоны } \\
\text { отдельных серий } \\
\text { отловов } \\
\text { [Years and seasons } \\
\text { of separate series } \\
\text { of captures] }\end{array}$} & \multicolumn{2}{|c|}{$\begin{array}{c}\text { Общая числен- } \\
\text { ность, экз. } \\
\text { [General number] }\end{array}$} & \multicolumn{2}{|c|}{$\begin{array}{c}\text { Численность по } \\
\text { методу Лесли, экз. } \\
\text { [Number of animals } \\
\text { according to Leslie method] }\end{array}$} & \multirow{2}{*}{$\begin{array}{c}\text { Численность по } \\
\text { методу Джолл- } \\
\text { Зебера, экз. ** } \\
\text { [Number of animals } \\
\text { according to Jolly- } \\
\text { Seber method] } \\
\text { Oпыт } \\
\text { [Experiment] }\end{array}$} \\
\hline & $\begin{array}{c}\text { Контроль } \\
\text { [Control] }\end{array}$ & $\begin{array}{c}\text { Опыт } \\
\text { [Experi- } \\
\text { ment] }\end{array}$ & $\begin{array}{c}\text { Контроль } \\
\text { [Control] }\end{array}$ & $\begin{array}{c}\text { Опыт } \\
\text { [Experiment] }\end{array}$ & \\
\hline & $N$ & $N$ & $\overline{-}$ & $\overline{-}$ & $\begin{array}{l}- \\
X\end{array}$ \\
\hline $\begin{array}{l}\text { Второй год, май, } \\
6-я \text { серия } \\
\text { [Second year May } \\
6 \text { series] }\end{array}$ & 0 & 19 & - & $18,01 \pm 0,63$ & $25,45 \pm 6,41$ \\
\hline $\begin{array}{l}\text { Второй год, июль, } \\
\text { 7-я серия } \\
\text { [Second year July } \\
7 \text { series] }\end{array}$ & 0 & 40 & - & $47,91 \pm 7,36$ & $40,0 \pm 0,42$ \\
\hline $\begin{array}{l}\text { Второй год, ноябрь, } \\
\text { 8-я серия } \\
\text { [Second year November } \\
8 \text { series] }\end{array}$ & 0 & 9 & - & $15,2 \pm 4,16$ & $13,5 \pm 4,3$ \\
\hline $\begin{array}{l}\text { Третий год, февраль, } \\
\text { 9-я серия } \\
\text { [Third year February } \\
9 \text { series] }\end{array}$ & 1 & 12 & - & $16,63 \pm 1,85$ & $24 \pm 13,87$ \\
\hline $\begin{array}{l}\text { Tретий год, май, } \\
10-я \text { серия **** } \\
\text { [Third year May } \\
10 \text { series] }\end{array}$ & 5 & 33 & $5,6 \pm 1,2$ & $61,9 \pm 32,54$ & $33 \pm 0,69$ \\
\hline
\end{tabular}

Примечание. ${ }^{*}$ - по регламенту опытов численность полевок рассчитывали на одной из двух идентичных половин экспериментальной и соответственно контрольной площадок мечения; общая площадь опытной площадки составляла 1 га; общая площадь контрольной площадки - 1 га; ** - численность животных по Джолли-Зеберу рассчитана только на экспериментальной площадке по причине слишком низкой численности грызунов в контроле; ${ }^{* * *}$ - внесение первой порции подкормки; $* * * *-$ внесение последней порции подкормки; $\bar{X}-$ средняя \pm ошибка средней. Уровень значимости отличия статистик от нуля по t-критерию приведен в тексте. $\mathrm{N}$ - точное число животных

[Note. * under experiment regulations the number of voles was counted on one of two identical halves of experimental and correspondingly control plots; the total area of the experimental plot - 1 hectare; the total area of the control plot - 1 hectare; **the number of animals according to Jolly-Seber method was calculated only on the experimental plot because of too low number of rodents in the control; *** addition of the first portion of supplemental food; **** addition of the last portion of supplemental food; $\bar{X}$ - mean value \pm error of the mean. The significance of differences, estimated by Student's $t$ test is found in the text. $\mathrm{N}$ - the exact number of animals].

Концентрация полевок в таких стациях может вызывать эффект роста локальной численности, что зафиксировано нами на опытном участке. Исходя из этого, площадку с подкормкой можно рассматривать в качестве экс- 
периментально сформированного в природных условиях аналога типичных «стаций переживания» грызунов. В данном случае особо следует выделить то, что в расчетах по методу Джолли-Зебера учитываются и те меченные ранее особи, которые в текущий период отловов не фиксируются, но в следующие серии отловов вновь обнаруживаются в пробах. Ранее нами установлен факт того, что за 4-5 сут непрерывных серий отловов в ловушки попадаются и получают метки все оседлые полевки. Следовательно, оценки по методу Джолли-Зебера являются несколько завышенными и на самом деле характеризуют не действительную или абсолютную численность (плотность) грызунов на участке мечения в данную конкретную серию проведения отловов, а общее число животных, длительное время так или иначе периодически использующих ресурсы территории с искусственно завышенной кормообеспеченностью.

Перечисленные факты могут служить аргументом для обоснования обнаруженного нами явления возвратной ротации населения грызунов. Данное явление позволяет ведущим подвижный образ жизни животным попеременно периодически использовать ресурсы предпочитаемой территории и при этом окончательно не терять с ней связь, так как подавляющее большинство природных биогеоценозов являются принципиально открытыми экосистемами. Открытость местообитаний грызунов при проведении наших экспериментов обеспечивалась тем, что площадки мечения не имели ограждения. Таким образом, эффект действия возвратной ротации позволяет аргументированно объяснить рост численности по Джолли-Зеберу осенью и зимой первого года исследований, когда общая (генеральная) численность сначала значительно снизилась, а затем находилась до конца года на одном уровне (см. таблицу). В эти периоды не все животные концентрировались на участке с подкормкой, что было бы невозможно, учитывая суммарную численность всех помеченных полевок и экологическую емкость среды обитания.

Как установлено ранее [33], центральную ротационную зону с подкормкой и статистически значимо более высокой плотностью населения грызунов (t-критерий $=11,2 ; \mathrm{p}<0,01)$ окружала значительно более обширная «буферная» периферическая ротационная зона с меньшей концентрацией животных и фоновой кормообеспеченностью. Состав населения в этой переходной периферической зоне, как и в центральной, не был постоянным из-за периодического перемещения животных из одной зоны в другую. За счет такого обмена определенная по методу Джолли-Зебера численность потребляющих ресурсы опытной площадки полевок в 3 и 5 раз соответственно превышала общую численность животных во время 2-й и 3-й серий отловов, которые проводились в экстремально сложный для выживания грызунов период середины зимы. Именно данный способ использования ресурсов территории с повышенной кормообеспеченностью позволил находящимся под постоянным наблюдением лесным полевкам на основе самоорганизации и саморегуляции сохранить предельно высокий уровень общей численности 
с августа первого года экспериментальных исследований до конца февраля второго года. При этом уже во время проведения 4-й серии отловов общая численность находилась на одном уровне с численностью по Джолли-Зеберу (см. таблицу). К данному периоду за счет увеличения естественной смертности зимой суммарная ротационная численность всех потреблявших подкормку полевок из двух упомянутых выше ротационных зон снизилась и пришла в соответствие с экологической емкостью опытного участка. В peзультате восстановления баланса этих показателей концентрация меченых грызунов на опытной площадке увеличилась практически в 3 раза по сравнению с предыдущей серией отловов, и общая численность животных достигла начального уровня, который зафиксирован в августе первого года до начала опытов.

Наряду с этим следует отметить, что в отсутствие каких-либо ограждений население грызунов на опытном участке и непосредственно вокруг него сохраняло свойства континуума. В условиях практически полного отсутствия другого населения полевок в районе проведения исследований (доказано путем проведения отловов на специальных учетных линиях ловушек) находящуюся под наблюдением структурную единицу населения можно охарактеризовать как локальный континуум населения. Вместе с тем данный конкретный структурный континуум функционировал в режиме экспериментально заданного резкого перепада кормообеспеченности местообитаний грызунов. В естественных биотопах, напротив, чаще всего наблюдаются постепенные переходы показателей кормовой емкости среды обитания животных. Данное обстоятельство позволяет с учетом рассматриваемого нами пространственного масштаба из общего понятия градиента средовых факторов выделить локальный градиент. В случае сочетания его с локальным континуумом видового населения появляется возможность в качестве объектов изучения рассматривать в том числе и локальные градиентные континуумы населения определенных видов. В отношении рыжей полевки удобными модельными объектами для изучения локальных градиентных континуумов населения могут служить отдельные стации переживания. В данном случае в качестве примера можно предложить такую сформированную нами с использованием трофического фактора стацию переживания. Учет того, что она создавалась в условиях природных биогеоценозов при минимальных вмешательствах с модификацией только одного трофического фактора, позволяет рассматривать территорию опытной площадки в качестве адекватного аналога реально существующих в природе стаций переживания. В рамках предлагаемого нами концептуального подхода именно на основе таких локальных и дискретно расположенных стаций происходит формирование и функционирование динамичной сети, состоящей из отдельных элементарных хорологических ячеек видового населения грызунов.

Дальнейшие исследования показали, что начиная с весны второго года проведения опытов (5-я серия отловов) вплоть до окончания работы общая 
(генеральная) или ротационная численность грызунов находилась на одном уровне с численностью по Лесли и Джолли-Зеберу (см. таблицу). Сначала она закономерно снизилась в апреле по причине естественно возросшей смертности грызунов в период снеготаяния. Затем это снижение продолжилось в мае (6-я серия отловов) из-за увеличения территориальной активности полевок в связи с началом сезона размножения. В конце июля (7-я серия отловов) все используемые показатели свидетельствовали о достижении высокого уровня численности лесных полевок в результате интенсивного хода процессов размножения на опытном участке. В дальнейшем на этой территории к концу осени (8-я серия отловов) произошло значительное четырехкратное снижение общей численности грызунов в условиях практически полного отсутствия лесных полевок в окрестностях площадок мечения. Однако уже к середине февраля третьего года проведения опытов (9-я серия отловов) произошло нетипичное увеличение численности грызунов за счет непосредственно зафиксированного подснежного размножения полевок на площадке с подкормкой. Следствием этого явилось практически четырехкратное (по сравнению с 8-й серией отловов) увеличение общей численности лесных полевок к заключительной 10-й серии отловов. В связи с этим необходимо отметить, что на контрольной площадке в условиях фоновой кормообеспеченности глубокая депрессия численности (вплоть до нулевых значений) всех видов грызунов продолжалась с конца первого года наблюдений до окончания экспериментальной части исследований (см. таблицу), или подряд 17 месяцев из 21.

Таким образом, результаты полевых экспериментов, на наш взгляд, достаточно обоснованно свидетельствуют о том, что ведущим экологическим фактором образования стаций переживания грызунов является трофический фактор. Воздействия только его одного при достижении порогового уровня кормообеспеченности оказывается достаточно для долговременного (два года и более) существования постоянно действующих стаций переживания на основе генетической преемственности нескольких последовательных поколений полевок. Причем размер реально действующих стаций может составлять от одного до нескольких гектаров.

\section{Заключение}

Установлено, что на территории отдельных стаций переживания неблагоприятных условий формируются автономные элементарные хорологические ячейки видового населения грызунов, которые в осенне-зимний период функционируют по принципу локального градиентного континуума населения вида. Последовательное формирование таких ячеек (хорусов) начинается осенью в период стадии локализации (агрегации) населения лесных полевок и заканчивается весной до схода снежного покрова и начала процессов размножения, когда размеры отдельных ячеек становятся минимальными. 
Вслед за этим начинается ежегодная стадия расселения, или экспансии, видового населения лесных полевок, которая закономерно сменяется следующей стадией локализации с облигатным формированием преемственной сети обновленных элементарных хорологических единиц видового населения - хорусов.

\section{Лumepamypa}

1. Elton C.S. Periodic fluctuations in numbers of animals: their causes and effects // Brit. J. Exper. Biol. 1924. Vol. 2. P. 119-163.

2. Wright S. Evolution in Mendelian populations // Genetics. 1931. Vol. 16, № 1. P. 97-159.

3. Наумов Н.П. Пространственные особенности и механизмы динамики численности наземных позвоночных // Журн. общ. биол. 1965. Т. 26, № 6. С. 625-633.

4. Швари С.С. Популяционная структура вида // Зоол. журн. 1967. Т. 46, № 10. С. 14561469.

5. Наумов Н.П. Пространственная структура вида млекопитающих // Зоол. журн. 1971. T. 50, № 7. C. 965-980.

6. Швари С.С., Гурвич Э.Д., Ищенко В.Г., Сосин В.Ф. Функциональное единство популяций // Журн. общ. биол. 1972. Т. 33, № 1. С. 3-14.

7. Флинт B.E. Пространственная структура популяций мелких млекопитающих. М. : Наука, 1977. $182 \mathrm{c.}$

8. Яблоков А.В., Баранов А.С., Розанов А.С. Популяционная структура вида (на примере Lacerta agilis L.) // Журн. общ. биол. 1981. T. 42, № 5. C. 645-656.

9. Садыков О.Ф., Бененсон И.Е. Динамика численности мелких млекопитающих: концепции, гипотезы, модели. М. : Наука, 1992. 191 с.

10. Жигальский O.A. Анализ популяционной динамики мелких млекопитающих // Зоол. журн. 2002. Т. 81, № 9. С. 1078-1106.

11. Чернявский Ф.Б., Лазуткин А.Н. Циклы леммингов и полевок на Севере. Магадан : ИБПС ДВО РАН, 2004. 150 c.

12. Krebs C.J. Population fluctuations in rodents. Chicago : Chicago Press, 2013. 306 p.

13. Оленев Г.В., Григоркина Е.Б. Функциональные закономерности жизнедеятельности популяций грызунов в зимний период // Экология. 2014. № 6. С. 428-438.

14. Лукьянова Л.Е., Бобрецьов А.В. Выбор рыжей полевкой (Clethrionomys glareolus Shreber, 1780) микроместообитаний в стабильных и дестабилизированных условиях среды // Вестник Томского государственного университета. Биология. 2014. № 4. (28). C. $88-107$.

15. Фрисман Е.Я., Неверова Г.П., Кулаков М.П., Жигальский О.А. Явление мультирежимности в популяционной динамике животных с коротким жизненным циклом // Доклады Академии наук. 2015. Т. 460, № 4. С. 488-493.

16. Hanski I. Metapopulation dynamics // Nature. 1998. № 396. P. 41-49.

17. Hanski I., Gaggiotti O. Ecology, Genetics and Evolution of Metapopulations. San Diego : Elsevier Academic Press, 2004. 696 p.

18. Добринский Н.Л. Элементарная хорологическая структура видового населения на примере полевок // Экология. 2010. № 3. С. 212-218.

19. Формозов А.Н. Очерк экологии мышевидных грызунов - носителей туляремии // Материалы по грызунам. М., 1947. Вып. 1. С. 1-19.

20. Штильмарк Ф.Р. Основные черты экологии мышевидных грызунов в кедровых лесах Западного Саяна // Фауна кедровых лесов Сибири и ее использование. М., 1965. C. 5-52. 
21. Смирин Ю.М. К биологии мелких лесных грызунов в зимний период // Фауна и экология грызунов. М., 1970. Вып. 9. С. 134-150.

22. Tast J., Kalela $O$. Comparisons between rodent cycles and plant production in Finnish Lapland // Ann. Acad. sci. fenn. 1971. Ser. A.Vol. 186. P. 1-29.

23. Владышевский Д.В. Экология лесных птиц и зверей (кормодобывание и его биоценотическое значение). Новосибирск : Наука, 1980. 264 с.

24. Сафронов В.M. Зимняя экология лесных полевок в Центральной Якутии. Новосибирск : Наука, 1983. 157 с.

25. Добринский Л.Н., Давыдов В.А., Кряжсимский Ф.В., Малафеев Ю.М. Функциональные связи мелких млекопитающих с растительностью в луговых биогеоценозах. М. : Наука, 1983. $160 \mathrm{c.}$

26. Абатуров Б.Д., Магомедов М.-Р.Д. Питательная ценность и динамика кормовых ресурсов как фактор состояния популяций растительноядных млекопитающих // Зоол. журн. 1988. Т. 67, № 2. С. 223-234.

27. Наумов Н.П. Очерки сравнительной экологии мышевидных грызунов. М. ; Л.: Изд-во AH CCCP, 1948. $203 \mathrm{c}$.

28. Наумов Н.П. Новый метод изучения экологии лесных грызунов // Фауна и экология грызунов. Материалы по грызунам. МОИП. 1951. Вып. 4. С. 3-21.

29. Leslie P.H., Davis D.H. An attempt to determine the absolute number of rats on a given area // J. Anim. Ecol. 1939. Vol. 8. P. 94-113.

30. Hayne D.W. Two methods for estimating populations from trapping records // J. Mammal. 1949. Vol. 30. P. 399-411.

31. Jolly G.M. Explicit estimates from capture-recapture data with both death and immigrationstochastic model // Biometrika. 1965. Vol. 52. P. 225-247.

32. Seber G.A. A note on the multiple-recapture census // Biometrika. 1965. Vol. 52. P. 249-259.

33. Добринский Н.Л. Локальная хорологическая структура населения и динамика пространственного распределения грызунов // Вестник Удмуртского университета. Сер. Биология. Науки о Земле. 2013. № 6-2. С. 81-88.

Поступила в редакичию 23.04.2015 2.; повторно 25.09.2015 2.; принята 15.10.2015 2.

Добринский Николай Львович - канд. биол. наук, с.н.с. лаборатории популяционной экологии и моделирования Института экологии растений и животных УрО РАН (г. Екатеринбург, Россия).

E-mail: dobrin@ipae.uran.ru

Dobrinskii NL. The tropic factor and local chorological structure of the population of rodents as exemplified by bank voles. Vestnik Tomskogo gosudarstvennogo universiteta. Biologiya - Tomsk State University Journal of Biology. 2015;4(32):62-75. doi: 10.17223/19988591/32/3. In Russian, English summary

\section{Nikolay L. Dobrinskii}

Institute of Plant and Animal Ecology, Ural Branch of the Russian Academy of Sciences, Yekaterinburg, Russian Federation

\section{The tropic factor and local chorological structure of the population of rodents as exemplified by bank voles}

Problems of organization and dynamics of the species population of vertebrate animals remain debatable and take a special significance after origination of metapopulation ecology. The trophic factor is one of the main ecological factors. Therefore, great importance of quantitative estimation of its contribution to functioning "stations of surviving" still exists as, most probably, such stations play the main role in the formation of local chorological structure of the species population of rodents. 
Thereupon, the exact quantitative estimation of the processes of formation and functioning of basic elementary chorological units of the species population by the example of the bank vole (Clethrionomys glareolus Schreber, 1780) was the purpose of our work. For this aim, under conditions of a typical southern taiga in the Middle Urals within the framework of continuous (from 1983 to 2014) monitoring studies, all-theyear-round field experiments with the use of strictly dosed additional food supply were conducted. We used a technique of lifelong marking and repeated catching of rodents on stationary unenclosed control and experimental plots with the sizes from 0.5 to 1 ha. Annually, from 2 to 5 catching series on each plot were carried out from February till December. For all the period of field experiments we caught and marked more than 500 bank voles and fixed more than 1500 animal trappings. As a result of simultaneous use of both regression and stochastic methods, the phenomenon of returnable rotation of the population of rodents with the formation of central and peripheral transitive zones was revealed for the first time. We established that the number of voles in the central zone with supplemental food was significantly above (t-student criterion $=11.2 ; \mathrm{p}<0.01$ ) in comparison with the neighboring peripheral zone without supplemental food. Such way of using the territory provides the species population, during the snow period, with the most effective consumption of trophic resources with maintaining the local abundance at a maximum level. Within the bounds of our conceptual approach, station environment of surviving, artificially formed with the help of using supplemental food, can be considered as adequate analogue to stations of surviving unfavorable conditions, what is real-life in nature. On the basis of such autonomic and discretely located stations there is a formation and functioning of the dynamical network consisting from elementary chorological units of the species population of rodents. The obtained results allow considering autonomous settlements of rodents in the sizes from 1 to several hectares as local gradient continuums of the species population. We found out that the leading ecological factor of forming elementary chorological units of the species population is the trophic factor. We showed that after reaching the necessary level of food supply there is obligatory formation of constantly functioning elementary chorological units of population on the basis of genetic continuity of several consecutive generations. Formation of elementary units begins in the autumn at the stage of localization of the bank vole population and comes to an end in the spring before snow cover melting and before the beginning of reproduction processes when the sizes of separate units become minimum. After this, the annual stage of dispersion or expansion of the species population of bank voles begins which is then appropriately replaced by the following stage of localization with obligatory formation of successive network of renewed elementary chorological units of the species population.

The article contains 1 Table, 33 References.

Key words: trophic factor; rodents; population; dynamics of abundance; experiments; additional food resources.

\section{References}

1. Elton CS. Periodic fluctuations in numbers of animals: their causes and effects. Brit. J. Exper. Biol. 1924;2:119-163.

2. Wright S. Evolution in Mendelian populations. Genetics. 1931;16(1):97-159.

3. Naumov NP. Prostranstvennye osobennosti i mekhanizmy dinamiki chislennosti nazemnykh pozvonochnykh [Specific spatial features and mechanisms of population dynamics in terrestrial vertebrates]. Zhurnal obshchei biologii - Journal of General Biology. 1965;26(6):625-633. In Russian 
4. Shvarts SS. Populyatsionnaya struktura vida [Population structure of the species]. Zoologicheskii zhurnal. 1967;46(10):1456-1469. In Russian

5. Naumov NP. Prostranstvennaya struktura vida mlekopitayushchikh [Spatial structure of the species in mammals]. Zoologicheskii zhurnal. 1971;50(7):965-980. In Russian

6. Shvarts SS, Gurvich ED, Ishchenko VG, Sosin VF. Funktsional'noe edinstvo populyatsiy [Functional unity of populations]. Zhurnal obshchei biologii - Journal of General Biology. 1972;33(1):3-14. In Russian

7. Flint VE. Prostranstvennaya struktura populyatsiy melkikh mlekopitayushchikh [Spatial structure of small mammal populations]. Moscow: Nauka Publ.; 1977. 182 p. In Russian

8. Yablokov AV, Baranov AS, Rozanov AS. Populyatsionnaya struktura vida (na primere Lacerta agilis L.) [Population structure of the species (the example of Lacerta agilis L.)]. Zhurnal obshchei biologii - Journal of General Biology. 1981;42(5):645-656. In Russian

9. Sadykov OF, Benenson IE. Dinamika chislennosti melkikh mlekopitayushchikh: kontseptsii, gipotezy, modeli [Population dynamics of small mammals: concepts, hypotheses and models]. Moscow: Nauka Publ.; 1992. 191 p. In Russian

10. Zhigal'skiy OA. Analysis of population dynamics of small mammals. Zoologicheskii zhurnal. 2002;81(9):1078-1106. In Russian, English summary

11. Chernyavskiy FB, Lazutkin AN. Tsikly lemmingov i polevok na Severe [Lemming and vole population cycles in the North]. Magadan: IBPS DVO RAN Publ.; 2004. 150 p. In Russian

12. Krebs CJ. Population fluctuations in rodents. Chicago: Chicago Press; 2013. 306 p.

13. Olenev GV, Grigorkina EB. Functional patterns of life activities of rodent populations in the winter season. Russian J. Ecology. 2014;45(6):480-489. doi: 10.1134/S1067413614060101

14. Lukyanova LE, Bobretsov AV. Microhabitat selection by the bank vole (Clethrionomys glareolus Schreber, 1780) under destabilized and stable habitat conditions. Vestnik Tomskogo gosudarstvennogo universiteta. Biologiya - Tomsk State University Journal of Biology. 2014;4(28):88-107. In Russian, English summary

15. Frisman EYa, Neverova GP, Kulakov MP, Zhigalskii OA. Multimode phenomenon in the population dynamics of animals with short live cycles. Doklady Biological Sciences. 2015;460:42-47. doi: 10.1134/S0012496615010111

16. Hanski I. Metapopulation dynamics. Nature. 1998;396:41-49. doi: 10.1038/23876

17. Hanski I, Gaggiotti O. Ecology, genetics and evolution of metapopulations. San Diego: Elsevier Academic Press; 2004. 696 p.

18. Dobrinskii NL. The elementary chorological structure of a species population as exemplified by voles. Russian J. Ecology. 2010;41(3):249-255. doi: 10.1134/S1067413610030094

19. Formozov AN. Ocherk ekologii myshevidnykh gryzunov - nositeley tulyaremii [Essay on the ecology of murine rodents-carriers of tularemia]. In: Materialy po gryzunam [Materials on rodents]. Formozov AN, editor. Moscow: Nauka Publ.; 1947. pp. 1-19. In Russian

20. Shtil'mark FR. Osnovnye cherty ekologii myshevidnykh gryzunov v kedrovykh lesakh Zapadnogo Sayana [Main features of the ecology of murine rodents in pine forests of the Western Sayan]. In: Fauna kedrovykh lesov Sibiri i ee ispol'zovanie [Fauna of cedar forests in Siberia and its use]. Moscow: Nauka Publ.; 1965. pp. 5-52. In Russian

21. Smirin YuM. K biologii melkikh lesnykh gryzunov v zimniy period [On biology of small forest rodents in winter period]. In: Fauna i ekologiya gryzunov [Fauna and ecology of rodents]. Vol. 9. Voronova AG, Zimina RP, Kucheruk VV, Formozov AN, editors. Moscow: Moscow State University Publ.; 1970. pp. 134-150. In Russian

22. Tast J, Kalela O. Comparisons between rodent cycles and plant production in Finnish Lapland. Ann. Acad. Sci. fenn. 1971;186:1-29.

23. Vladyshevskiy DV. Ekologiya lesnykh ptits izverey (kormodobyvanie i ego biotsenoticheskoe znachenie) [Ecology of forest birds and animals (foraging and its biocenotic meaning)]. Novosibirsk: Nauka, Siberian Branch Publ.; 1980. 264 p. In Russian 
24. Safronov VM. Zimnyaya ekologiya lesnykh polevok v Tsentral'noy Yakutii [Winter ecology of red-backed voles in Central Yakutia]. Novosibirsk: Nauka, Siberian Branch Publ.; 1983. 157 p. In Russian

25. Dobrinskiy LN, Davydov VA, Kryazhimskiy FV, Malafeev YuM. Funktsional'nye svyazi melkikh mlekopitayushchikh s rastitel'nost'yu v lugovykh biogeotsenozakh [Functional connections of small mammals with vegetation in meadow biogeocenoses]. Moscow: Nauka Publ.; 1983. 160 p. In Russian

26. Abaturov BD, Magomedov M-R D. Pitatel'naya tsennost' i dinamika kormovykh resursov kak faktor sostoyaniya populyatsiy rastitel'noyadnykh mlekopitayushchikh [Nutritional value and dynamics of food resources as a factor of the population state of herbivorous mammals]. Zoologicheskii zhurnal. 1988;67(2):223-234. In Russian

27. Naumov NP. Ocherki sravnitel'noi ekologii myshevidnykh gryzunov [Essays on comparative ecology of murine rodents]. Moscow: Akad. Nauk SSSR Publ.; 1948. 203 p. In Russian

28. Naumov NP. Novyy metod izucheniya ekologii lesnykh gryzunov [A new method for studying the ecology of forest rodents]. In: Fauna i ekologiya gryzunov [Fauna and ecology of rodents]. Formozov AN, editor. Moscow: Izdatel'stvo MOIP Publ.; 1951. pp. 3-21. In Russian

29. Leslie PH, Davis DH. An attempt to determine the absolute number of rats on a given area. J. Anim. Ecol. 1939;8:94-113.

30. Hayne DW. Two methods for estimating populations from trapping records. J. Mammal. 1949;30:399-411.

31. Jolly GM. Explicit estimates from capture-recapture data with both death and immigration stochastic model. Biometrika. 1965;52:225-247.

32. Seber GA. A note on the multiple-recapture census. Biometrika. 1965;52:249-259.

33. Dobrinskiy NL. Local chorological structure of the population and dynamics of a spatial distribution of rodents. Vestnik Udmurtskogo universiteta. Seriya Biologiya. Nauki o zemleBulletin of Udmurt University. Biology \& Earth Sciences. 2013;6-2:81-88. In Russian

Received 23 April, 2015; Revised 25 September, 2015; Accepted 15 October 2015

\section{Autor info:}

Dobrinskii Nikolay L, Cand. Sci. (Biol.), Senior Researcher, Laboratory of Population Ecology and Modeling, Institute of Plant and Animal Ecology, Ural Branch of the Russian Academy of Sciences, 8 Marta Str., Yekaterinburg 620144, Russian Federation.

E-mail: dobrin@ipae.uran.ru 